\title{
Five-Level Single Source Voltage Converter Controlled Using Selective Harmonic Elimination
}

\author{
Ibrahim Haruna Shanono1, Nor Rul Hasma Abdullah², Aisha Muhammad ${ }^{3}$ \\ ${ }^{1,2}$ Faculty of Electrical and Electronics Engineering, Universiti Malaysia Pahang, 26600 Pekan, Pahang, Malaysia \\ ${ }^{1}$ Department of Electrical, Faculty of the Engineering, Bayero University Kano, Nigeria \\ ${ }^{3}$ Department of Mechatronics, Faculty of the Engineering, Bayero University Kano, Nigeria
}

\begin{tabular}{l} 
Article Info \\
\hline Article history: \\
Received May 1, 2018 \\
Revised Jun 19, 2018 \\
Accepted Aug 25, 2018 \\
\hline
\end{tabular}

\section{Keywords:}

Multilevel topology

Voltage source converters

Modulation technique

Reduced device count

\begin{abstract}
The paper presents a 5-level cascaded H-bridge voltage source inverter. The converter topology composed of two-cascaded H-bridge modules connected in parallel and powered by a single DC source. The benefit of this topology in comparison with the conventional H-Bridge configuration is that it uses single input DC source instead of two to achieve the same output steps/levels. Selective Harmonic Elimination (SHE) is the modulation technique employed. The generated non-linear transcendental equations are solved using an optimised Genetic algorithms to find the switching angles. This property makes the topology and the control function suitable for three phase applications where triplen harmonics are said to cancel out at the lineto-line voltages. This concept of SHE modulation extends the value of the filter cut-off frequency, which translates to smaller sized filter, compact cooling system and reduced system weight. This advantage makes the topology attractive to automotive and renewable energy applications. The topology was simulated using PSIM software.
\end{abstract}

Copyright $\odot 2018$ Institute of Advanced Engineering and Science. All rights reserved.

\section{Corresponding Author:}

Ibrahim Haruna Shanono,

Faculty of Electrical and Electronics Engineering,

Universiti Malaysia Pahang,

26600 Pekan, Pahang, Malaysia.

Email: snnibrahim01@gmail.com

\section{INTRODUCTION}

A Multi-level Inverter (MLI) can merely be described as an electrical device comprising of power electronic switches arranged and controlled systematically, such that it converts a Dc input source coming from either photovoltaic cells, batteries, capacitors etc. into multiple stepped output voltage waveform close to a sinusoidal signal. Multilevel inverter popularity is due to the various advantages it offered over the conventional square wave inverter. The converter modular nature coupled with the advances made in semiconductor technology has broadened up its usage in high power industrial applications. Moreover, it provides less switching stress on power switches, therefore reducing switching losses in the circuit which improves the system efficiency. It reduced output total harmonic distortion (THD), and electromagnetic interference (EMI) makes it suitable for highly sensitive applications [1]-[3].

Baker's in the mid 70's proposed Cascaded H-bridge (CHB) topology which he published in a patent titled 'Electric power converters' [4]. It was the first inverter topology to generates multiple output steps using more than one Dc source. Later in the 80 's, they proposed another topology which is popularly known as Neutral point clamped converter (NPC) or Diode Clamped topology. The benefit of this topology over the earlier one is it uses single DC source with additional diodes and capacitors to achieve higher output voltage steps. In the same year, Nabae et al., applies the Pulse Width Modulation (PWM) control scheme on the NPC topology that produces an output with less harmonic distortion [5]. Most of the research done in the 80's were 
more focused towards three level converter topologies, but later in the 1990s, the number of steps was increased up to six levels [6].

In the 90's, a new topology was proposed by Meynard and Foch, which was called Flying Capacitor (FC) [7]. It circuit connection is similar to that of a Diode Clamp, only that the diodes were replaced with capacitors. One of the benefits of flying capacitor over diode clamp is its redundancy property. It can generate a particular output voltage using multiple switching sequences [8]. Most of the early literature was based on the above three mentioned topologies, which makes them be termed as classical topologies.

Recently, some new topologies were developed, most of which are application base driven. This is because a particular topology tends to be more effective and efficient in a specific application and unsuitable in another [9], [10]. Hence, making both academia and industry to explore more topologies that suits a particular application.

The positive impact MLI's are making at domestic and industrial level attracts more research interest which focuses on improving its topologies and control scheme. One major MLI limitation is the relationship between the number of components and the voltage output steps, which is said to be in a direct proportion to each other. Therefore, the circuit tends to be larger in size, complicated and more expensive. To overcome this limitation, researchers and engineers are developing new topologies with reduced device count [11], [12].

This paper is equally part of the same research, aiming at generating more output voltage step with fewer components. The article uses two modules of the H-bridge inverter, connected in parallel and both powered using a single DC source. The source could be either battery, photovoltaic cell or fuel cell. The two modules are controlled using switching angles obtained by solving the non-linear transcendental equations generated through SHE-PWM theorem, which eliminates $\mathrm{N}-1$ harmonics, with $\mathrm{N}$ been the number of switching angles. Various techniques exist for solving such non-linear equations that has several solutions due to their trigonometric nature [13], [14]. However, in this paper, an optimised genetic algorithm technique proposed in [15] was used to get the optimal solutions of the switching angles. The selective property of SHE-technique is employed where some selected lower order odd non-triplen harmonics were eliminated. Which further increase the output filter cut off frequency, hence reducing the system filter size. If the set up is transformed into three phase, it is expected that the output Triplen harmonics to cancel out in the line-toline voltage. Therefore, this paper presents a single-phase five level converter controlled using three SHEPWM control scheme. The study demonstrates the efficacy of the proposed topology and the G.A optimisation technique used in finding the optimal switching angles.

\section{MATERIALS AND METHODS}

\subsection{Proposed converter topology and circuit operations}

Figure 1 shows the converter topology used to achieve the five-level output waveform. The circuit comprises of two H-bridge modules connected in parallel and both supplied by a single Dc source. The source could either be a photovoltaic cell, rectified wind energy, fuel cell or lithium-ion batteries. The two modules comprise of eight power electronic switches, with each having four switches. Each module is capable of generating three output steps $(+\mathrm{E}, 0$, -E). The secondary transformer terminals are connected in series with each other and their respective voltages VP2 and VP3 are said to add up across the load. With proper switching function, the converter is capable of generating five level output waveform. The topology also offers additional switching redundant state, which could be used in fault situations.

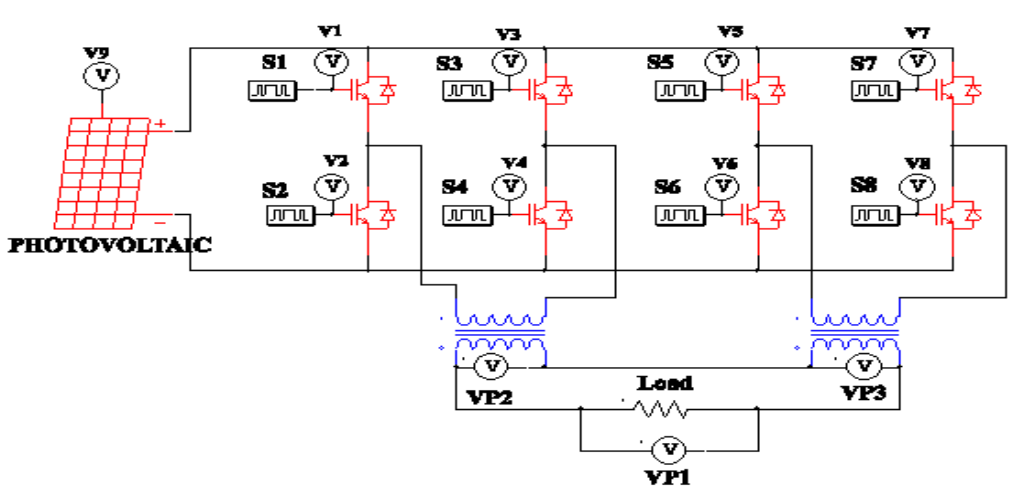

Figure 1. Proposed topology inverter configuration 
To synthesize the voltage waveform at the terminals, the gating signal of each IGBT needs to be generated based on the calculated switching angles. The IGBT's conduction states during the positive and negative half cycle in both $\mathrm{H}$-bridges are given in Table 1. However, other redundant switching states can as well be explored to address switching stress and failure rate of the switching devices. It is worth noting that switches on the same leg are operated complementarily to avoid short-circuiting the dc source.

Table 1. Selected switching combinations

\begin{tabular}{ccccccccc}
\hline Voltage & \multicolumn{1}{l}{ Switching states } \\
\hline \multirow{2}{*}{$\mathrm{S}_{1}$} & $\mathrm{~S}_{2}$ & $\mathrm{~S}_{3}$ & $\mathrm{~S}_{4}$ & $\mathrm{~S}_{5}$ & $\mathrm{~S}_{6}$ & $\mathrm{~S}_{7}$ & $\mathrm{~S}_{8}$ \\
$+\mathrm{E}$ & 1 & 0 & 1 & 0 & 1 & 0 & 1 & 0 \\
0 & 1 & 0 & 0 & 1 & 1 & 0 & 0 & 1 \\
$-\mathrm{E}$ & 0 & 1 & 0 & 1 & 0 & 1 & 0 & 1 \\
\hline
\end{tabular}

\subsection{Five level 3/9 Output voltage waveform design and switching angle calculation}

The modulation technique used in any converter topology played a significant role in the obtained output waveform [16]. In this case, selective harmonic elimination technique (SHE) is the method to be used to generate the five-level output voltage with $3 / 9$ angle distribution ratio. While trying to achieve the said output level, the power electronic switches are controlled such that the targeted selected harmonics are successfully eliminated. SHE apart from reducing THD in the output, it also minimises electromagnetic interference (EMI) and switching losses in the system [17], [18].

To generate the waveform with 3/9 switching distribution ratio, a rough sketch of the five-level waveform is initially made using arbitrary values of switching angles. Figure 2 depicts a rough sketch of the targeted waveform with the assumption that it obeys the quarter-wave symmetry theorem with twelve switching angles $\left(\alpha_{1}\right.$ to $\left.\alpha_{12}\right)$ per quarter cycle [18].

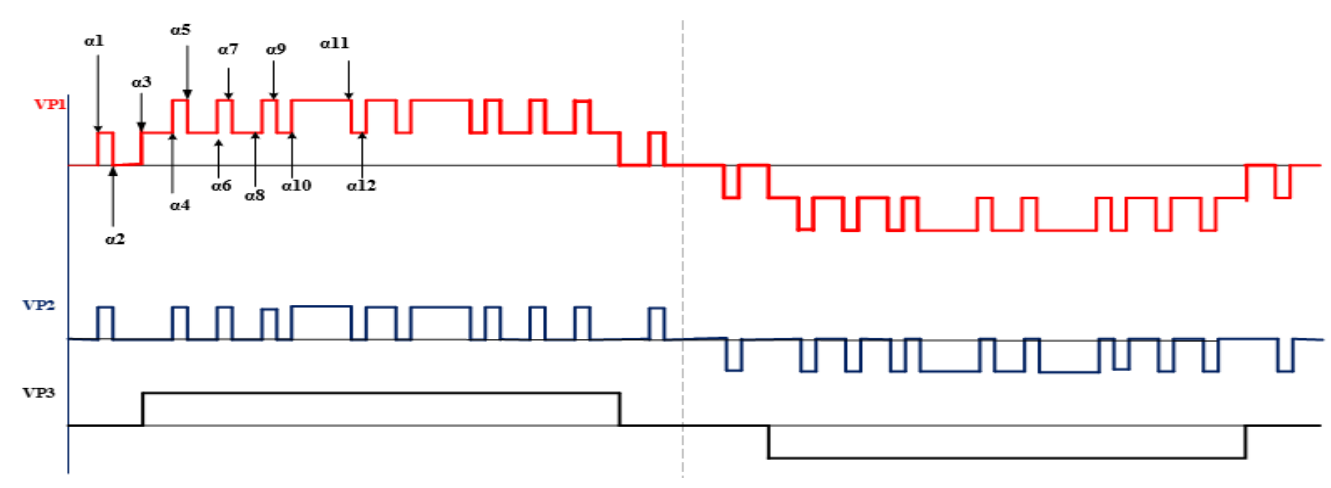

Figure 2. Five Levels waveform with 3/9 distribution ratio

Based on quarter wave theorem, sinusoidal signal results in DC and even harmonic components cancellation, the output components contain only the fundamental and odd harmonics [19]. To eliminate individual harmonics, the fundamental component needs to be systemically controlled during the positive and negative half cycles at specific angles. With this operation, the selected lower order (N-1) non-triple harmonics are eliminated, where $\mathrm{N}$ is the number of switching angles in a quarter wave [14], [17].

Therefore, the following harmonics $5^{t h}, 7^{t h}, 11^{\text {th }}, 13^{\text {th }}, 17^{\text {th }}, 19^{\text {th }}, 23^{\text {rd }}, 25^{\text {th }}, 29^{\text {th }}, 31^{\text {st }}, 35^{\text {th }}$ order are eliminated in the output. This further shifts the output filter cut off frequecy, hence reducing the system filter size. If the topology is transformed to three phase, it is expected that the output triplen harmonics will cancel out in the line-to-line voltage.

The Fourier series expansion of the five-level waveform in Figure 2 is generated using the expressions [20].

$$
V_{\text {out }}(w t)=\sum_{\mathrm{n}=1}^{\infty} a_{n} \sin (n w t)
$$


Where

$$
a_{n}=\frac{4 E}{n \pi} \sum_{K=1}^{N}(-1)^{K+1} \cos \left(n \alpha_{K}\right)
$$

for odd values of $n$

$$
b_{n}=0
$$

for all value of $n$

$\alpha_{\mathrm{K}}$ Denotes the switching angles and most satisfies the relationship,

$$
\alpha_{1}<\alpha_{2}<\ldots \ldots<\alpha_{N}<\frac{\pi}{2}
$$

E is the input dc supply voltage, $N$ is the switching angles per quarter wave, $n$ is the odd harmonic order, $w$ is the angular frequency, $t$ is time.

Simplifying Equation (1) and (2) The amplitude of the fundamental and non-triplen odd harmonic components in the five-level output waveform is represented by the non-linear transcendental equations given in Equation (5) and (6):

$$
\begin{aligned}
& h_{1}=\frac{4 * \mathrm{E}}{\pi}\left\{\cos \left(\alpha_{1}\right)-\cos \left(\alpha_{2}\right)+\ldots \ldots \pm \cos \left(\alpha_{12}\right)\right\} \\
& h_{1}=\frac{4 * \mathrm{E}}{\mathrm{n} \pi}\left\{\cos \left(n \alpha_{1}\right)-\cos \left(n \alpha_{2}\right)+\ldots \pm \cos \left(n \alpha_{12}\right)\right\}
\end{aligned}
$$

The amplitude of the fundamental component is controlled by the modulation index (M) and is given by the expression.

$$
\begin{aligned}
& \text { Modulation Index }(M)=\frac{h_{1}}{E} \\
& \text { For all } n=1 \\
& \text { While } M=0 \text { for all } n+1
\end{aligned}
$$

Hence, using Equation (5), (6) and (7) the non-linear transcendental equations can be expressed as:

$$
\begin{aligned}
& \cos \left(\alpha_{1}\right)-\cos \left(\alpha_{2}\right)+\cos \left(\alpha_{3}\right)-+\cos \left(\alpha_{11}\right)-\cos \left(\alpha_{12}\right)=\frac{\mathrm{M} \pi}{4} \\
& \cos \left(5 \alpha_{1}\right)-\cos \left(5 \alpha_{2}\right)+\cos \left(5 \alpha_{3}\right)-. .+\cos \left(5 \alpha_{11}\right)-\cos \left(5 \alpha_{12}\right)=0 \\
& \vdots \\
& \vdots \\
& \cos \left(35 \alpha_{1}\right)-\cos \left(35 \alpha_{2}\right)+\cos \left(35 \alpha_{3}\right)-. .+\cos \left(35 \alpha_{11}\right)-\cos \left(35 \alpha_{12}\right)=0
\end{aligned}
$$

The above transcendental equations are solved to find the approximate solution of the switching angles, capable of eliminating the selected lower order harmonics. Given the nonlinearity and the trigonometric content of the equations, finding the solution using standard mathematical solution is not possible because multiple solutions exist. Therefore, to get the optimal values, a hybrid genetic algorithm presented in [15] was used to find the solution. The technique uses different values of overmodulation index (M) to find the solutions for the switching angles $\alpha_{1}, \alpha_{2}, \ldots, \alpha_{12}$.

\subsection{Module terminal voltages design and gating signals generation}

Figures $3 \mathrm{a}$ and $3 \mathrm{~b}$ are the expected waveforms at the terminals of module 1 and 2 with their corresponding gating signals. The terminal voltages add up to generate the five-level output voltage across the load. Both the terminal and gating signals were generated based on the switching combinations presented in Table 1. As seen, the majority of the notches comes from the first module. However, the research work is not after analysing the power-sharing and switching stress in the system. Its primary target is to employ SHEmodulation technique using less number of devices/components to achieve higher-level output with less output THD. Therefore, balancing the switching stress and power transfer is outside the scope of this paper. 


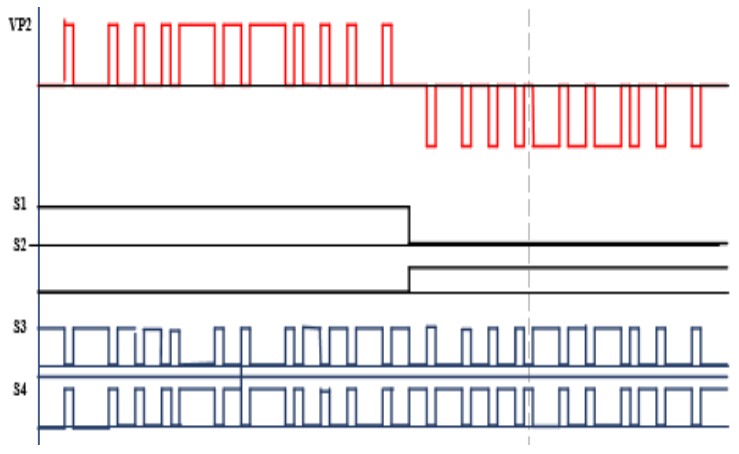

(a) Module 1 terminal voltage (V1) and gating signals

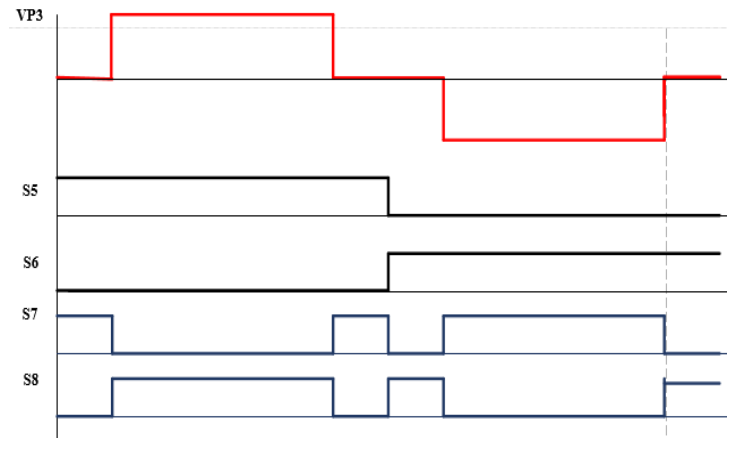

(b) Module 2 terminal voltage (V2) and gating signals

Figure 3. Designed converter terminal voltages

\section{RESULTS AND DISCUSSION}

\subsection{Switching Angles Solutions}

The generated equations as stated earlier were solved using an optimised genetic algorithm with $\mathrm{M}=3.2$. The solution provides 12 switching angles as shown in Table 2 . The remaining switching angles were obtained using quarter wave symmetry. These angles are directly fed into the PSIM software pulse generators to produce a $50 \mathrm{~Hz}$ gating signal. With the appropriate gate pulse, terminal voltages and gating signals similar to the ones in Figure $3 \mathrm{a}$ and $3 \mathrm{~b}$ are generated. The terminal voltages add up across the load to produce a five-level output waveform with $3 / 9$ distribution ratio. Depending on the harmonic coefficients used in the transcendental equation, 11 selected harmonics are eliminated from the converter output.

The computed angles are converted into the time domain, which is then programmed using $\mathrm{C}$ on a microcontroller to generate the pulsating signals.

\begin{tabular}{|c|c|}
\hline $\mathrm{s} / \mathrm{n}$ & $0-90$ \\
\hline$\alpha$ & \\
\hline 1 & 13.40246 \\
\hline 2 & 15.67567 \\
\hline 3 & 19.61681 \\
\hline 4 & 35.50001 \\
\hline 5 & 37.80673 \\
\hline 6 & 46.26136 \\
\hline 7 & 48.24797 \\
\hline 8 & 54.85481 \\
\hline 9 & 58.37752 \\
\hline 10 & 61.01313 \\
\hline 11 & 83.87128 \\
\hline 12 & 86.01930 \\
\hline
\end{tabular}

\subsection{Simulation Results}

The proposed topology modular terminal voltage waveforms VP2 and VP3, together with their corresponding IGBT control signals, are shown in Figure $4 \mathrm{a}$ and $4 \mathrm{~b}$, respectively. Both voltage waveforms look the same with the pre-sketched pattern presented in the methodology section. The gating signals for the eight IGBT's are switched in conformity with the computed angles and the voltage switching combination given in Table 1.

Figure 5a shows the five-level fundamental output voltage waveform across a resistive load. The fundamental voltage is chopped several times at a pre-calculated switching point, satisfying the 3/9 distribution ratio as sketched in Figure 2. Note that the output voltage across the load is expressed as the sum of both transformer secondary side voltages $V P 1=V P 2+V P 3)$. Figure $5 \mathrm{~b}$ depicts the output waveform along with a superimposed sinusoidal waveform and the output current in the lower plot. Due to high harmonic content, both voltage and current does not closely follow the pure sinewave pattern. 


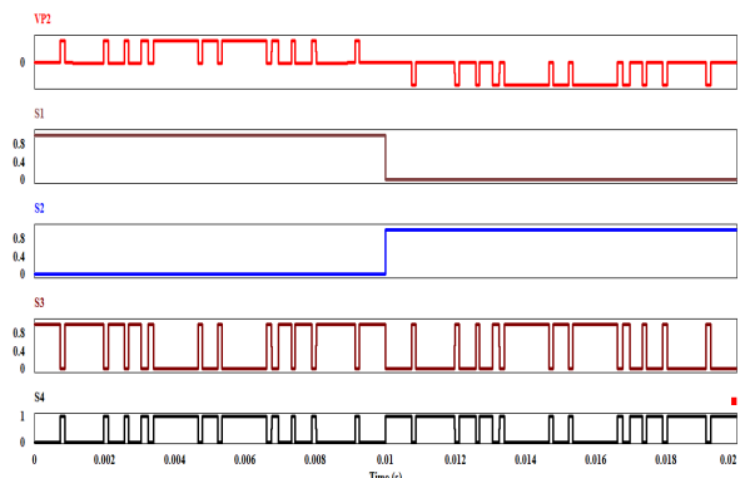

(a) Module1 (VP2) with gating signal

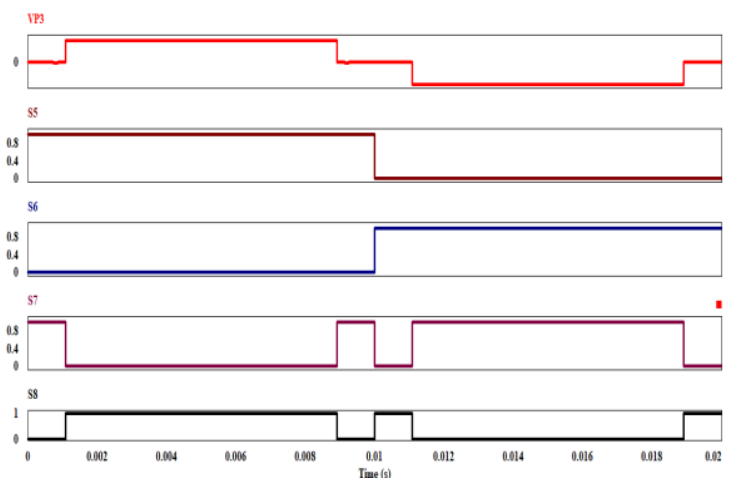

(b) Module2 (VP3) with gating signal

Figure 4. Simulated Converter Terminal Voltage
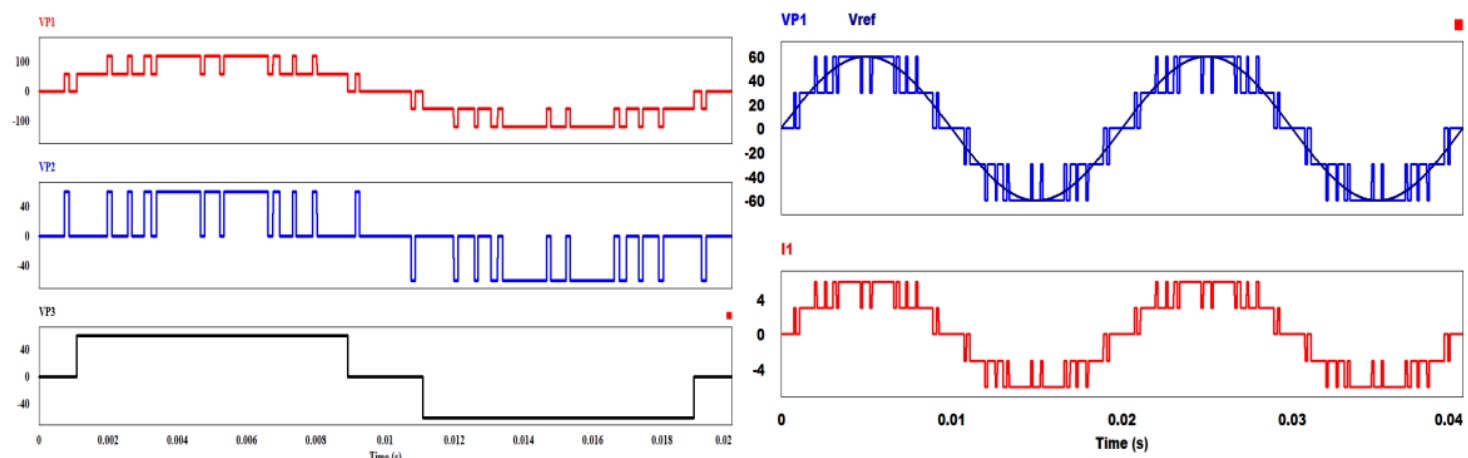

(a)

(b)

Figure 5. The proposed five-level waveform

Figure 6 shows the Fast Fourier transform (FFT) of the proposed five-level over the range of $5 \mathrm{KHz}$ at light loading. From the spectrum, SHE-PWM successfully eliminates all the 11 selected lower order odd non-triplen harmonics that lies within $1.75 \mathrm{KHz}$ (35th) range, leaving behind the triplens (3rd, 9th, 15th, 21st, $27 \mathrm{th}, 33 \mathrm{rd})$. The first dominant non-triplen harmonic visible is the $37 \mathrm{th}(1.85 \mathrm{KHz})$, and the spectrum becomes full of harmonics afterwards, hence, complying with the control function employed.

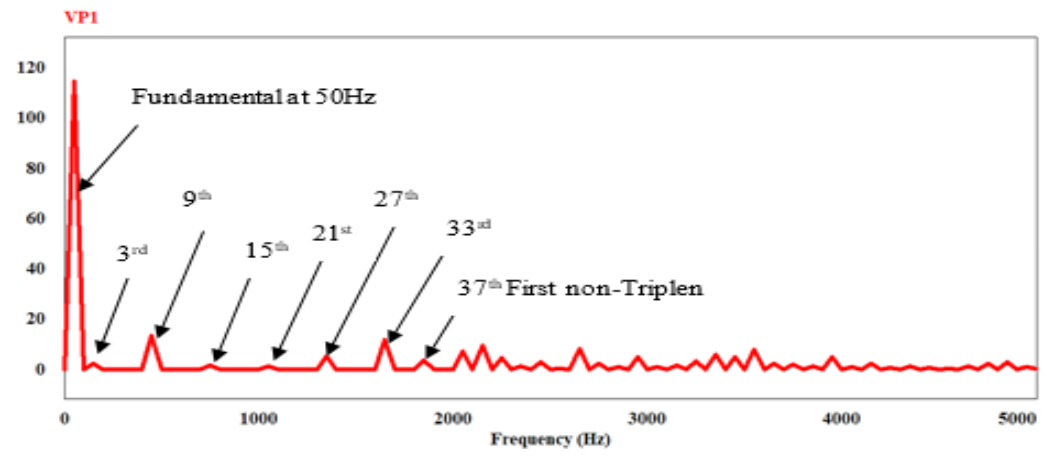

Figure 6. FFT Spectrum of the five-level waveform

However, since the harmonics are at a higher frequency, a small-sized low pass filter can be used to eliminate them. To demonstrate this, an LC filter is designed for the circuit. Figure 7a shows the filtered output voltage waveform and the current at full load. Both waves look closer to a pure sinewave than the unfiltered wave presented in Figure 5b. Figure 7b is the FFT of the filtered waveform; it appears to have less

Five-Level Single Source Voltage Converter Controlled Using Selective... (Ibrahim Haruna Shanono) 
harmonic contents with THD of $4.65 \%$ compared with the unfiltered FFT in Figure 6. Hence, the topology is said to satisfy the IEEE THD standard requirement of less than $5 \%$.

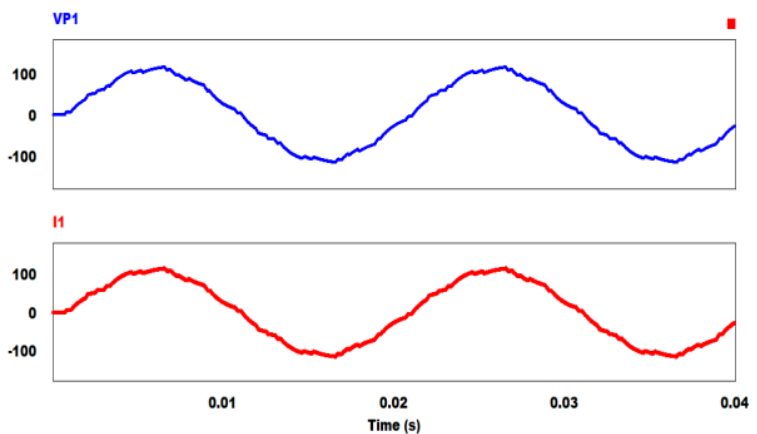

(a) Filtered output waveform

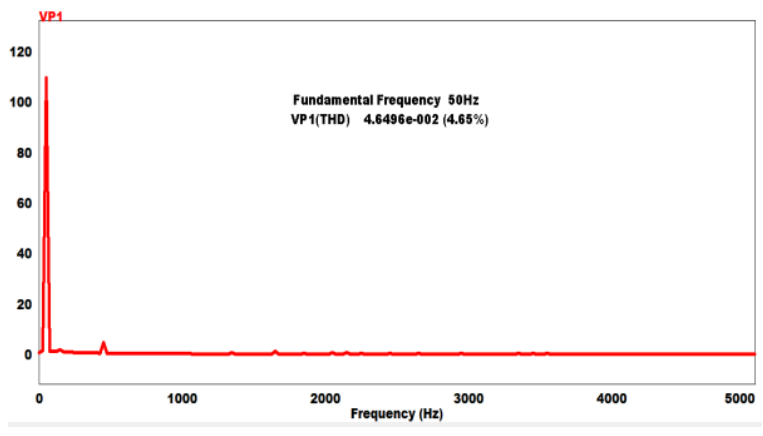

(b) FFT

Figure 7. Proposed topology

This control technique is suitable for 3-phase applications, where the triplen harmonics are said to cancel each other in the line voltages.

\subsection{Comparison between Conventional and Proposed topology}

The conventional H-bridge topology and the proposed has the same number of switching components; they differ in the number of input Dc sources and the switching function involved. In conventional, the number of input sources increases with increase in output levels, whereas, the proposed topology uses single Dc source irrespective of the number of output levels. Figure $8 \mathrm{a}$ is the conventional output voltage and current waveforms, while $8 \mathrm{~b}$ is the output voltage FFT with THD of $9.46 \%$.

The THD of the proposed $(4.65 \%)$ at the same output power is less than that of the conventional $(9.46 \%)$, and it can even be verifiable by physical assessment of both waveforms of Figures 7 and 8 .

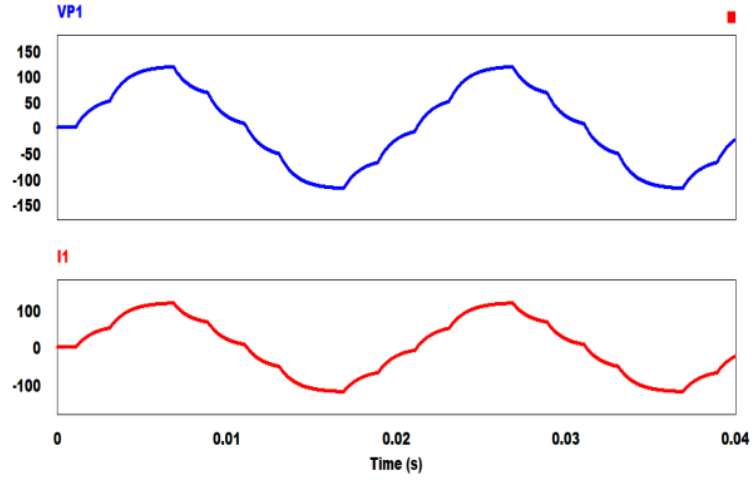

(a) Filtered output waveform

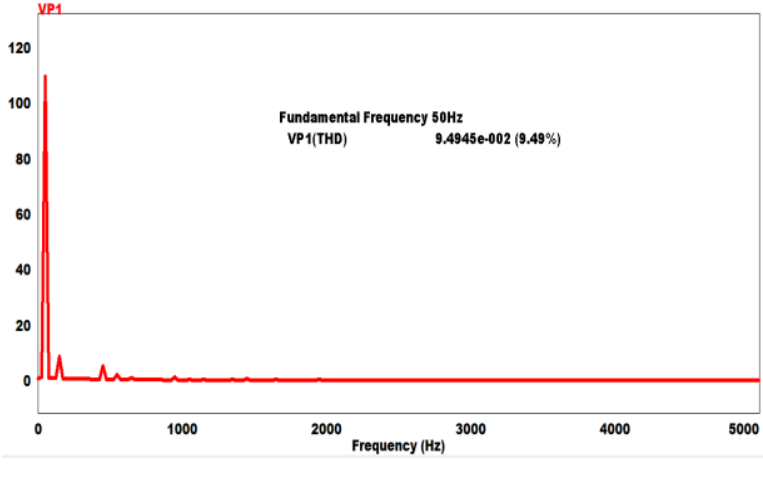

(b) FFT

Figure 8. Conventional topology

Usually, total harmonic distortion (THD) of an inverter decreases with increase in output power [18]. Figure 9a represents the THD vs output power curves of both the two topologies. The axis to the left represents that of the proposed topology whereas the right axis is for the conventional topology. From the graph, both topologies exhibit the fundamental property of decreasing THD with an increase in output power.

Figure $9 \mathrm{~b}$ shows the efficiency vs output power plots for the two topologies. Both curves conform to the standard inverter efficiency curve that initially raises from zero to a high value before it then stabilises as the output load increases. The proposed topology has better efficiency than the conventional at all loading 
level. The average efficiency value for the conventional and proposed stands at $49.2 \%$ and $99.1 \%$ respectively. The difference translates to over $100 \%$ improvement in efficiency with respect to the conventional. This further ascertains the viability of the proposed topology and the SHE modulation technique employed.

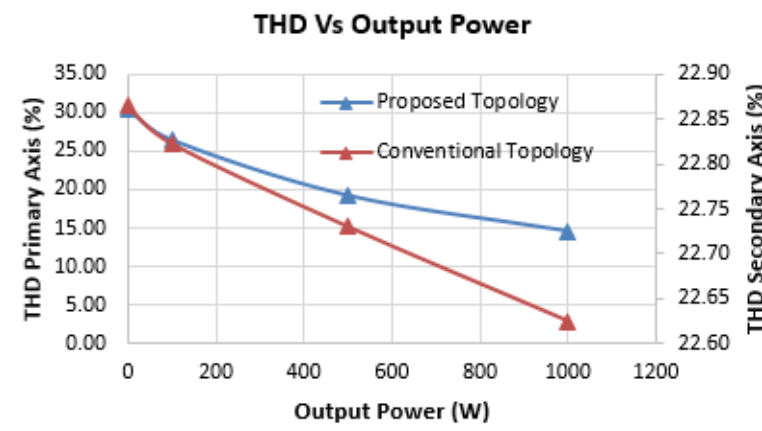

(a)

Figure 9. (a) THD Comparison

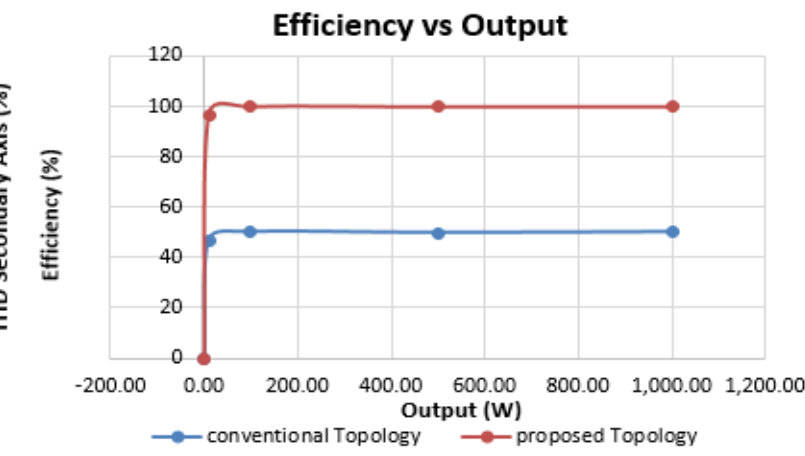

Figure 9. (b) Efficiency Comparison

\section{CONCLUSIONS}

A five-level multilevel converter using cascaded H-bridge topology with a single DC input source and multi-winding transformer was designed, simulated, and validated. The reported converter addressed the issue of converter size by using single Dc source to synthesise a five-level output voltage waveforms, hence eliminating the need for multiple sources. Based on the result obtained, it shows SHE-PWM has the capability of eliminating selected harmonics by adding some notches to the fundamental component at a specific pre-determined angle. The control function used targets odd non-triple lower harmonics, which makes it suitable for three phase applications where triplens cancels out in the line voltage. In addition to that, the converter is compact, has less switching stress and heat dissipation caused by harmonics. This results in a reduction in cooling requirements. Thus, translates to lesser size, weight, production and maintenance cost.

The proposed topology has satisfied the below 5\% THD level, which is one of the reason it has high efficiency. All the above features make the converter suitable and attractive to applications where reliability and efficiency are of uttermost importance.

\section{ACKNOWLEDGEMENTS} Pahang (UMP).

This work is supported by the Faculty of Electrical and Electronic Engineering, Universiti Malaysia

\section{REFERENCES}

[1] R. Palanisamy, K. Vijayakumar, D. Selvabharathi "MSPWM Based Implementation of Novel 5-level Inverter with Photovoltaic System", International Journal of Power Electronics and Drive Systems, vol.8, No.4, pp. 1494-1502, Dec. 2017.

[2] Shanono, I. H., Abdullah, N. H., Muhammad, A.,“ 9-Level Voltage Source Inverter Controlled Using Selective Harmonic Elimination" International Journal of Power Electronics and Drive Systems, Vol. 9, No. 3, pp. 1251-1262, Sept., 2018.

[3] Shanono, I. H., Abdullah, N. H., Muhammad, A.,“ A Survey of Multilevel Voltage Source Inverter Topologies,

[4] Controls and Applications" International Journal of Power Electronics and Drive Systems, Vol. 9, No. 3, pp. 11861201, Sept., 2018.

[5] Baker, R. H., and Bannister, L. H., "Electric power converter", U.S. Patent 3867 643, 1975.

[6] Nabae, A., Takahashi, I., and Akagi, H., "A neutral-point-clamped PWM inverter", in Proc. Conf. Rec. IEEE IAS Annual Meet., Cincinnati, OH, USA, pp. 761-766, 1980.

[7] Choi, N.S., Cho, J.G. and Cho, G.H., " A general circuit topology of multilevel inverter ", in 22nd IEEE Proc. Power Electron. Spec. Conf., Cambridge, MA, USA, pp. 96-103, 1991.

[8] Meynard, T. A., and Foch, H., "Multi-level conversion: High voltage choppers and voltage-source inverters", in Proc. IEEE Power Electron. Spec. Conf., Toledo, Spain, pp. 397-403, 1992. 
[9] Rodrigue et al., " Multilevel Converters: An Enabling Technology for High-Power Applications ", in IEEE Proceedings, pp. 1786-1817, 2009.

[10] G. Ramya, R. Ramaprabha, "A Review on Design and Control Methods of Modular Multilevel Converter" International Journal of Power Electronics and Drive Systems, Vol. 7, No. 3, pp. 863-871, Sept., 2016.

[11] R.A. Krishna, L.P. Suresh, "A Brief Review on Multi-Level Inverter Topologies", in 2016 International Conference on Circuit, Power and Computing Technologies (ICCPCT), Nagercoil, India, pp. 1-6, 2016.

[12] Ebrahimi, J., Babaei, E. and Gharehpetian, G.B., "A new multilevel converter topology with reduced number of power electronic components”,IEEE T Ind Electron, Vol. 59, no. 2, pp. 655-667, 2012.

[13] Kangarlu, M. F., and Babaei, E., "A generalized cascaded multilevel inverter using series connection of submultilevel inverters", IEEE T Power Electron., vol. 28, no. 2, pp. 625-636, 2013.

[14] Ozpineci, B., Tolbert, L.M. and Chiasson, J.N., " Harmonic optimisation of multilevel converters using genetic algorithms", IEEE Power Electron Lett. , Vol. 3, no. 3, pp. 92-95, 2005.

[15] Chiasson, J.N., Tolbert, L.M., McKenzie, K.J., and Du, Z., "A New Approach to Solving the Harmonic Elimination Equations for a multilevel Converter ", in 38th IAS Annual Meeting on Conference Record of the Industry Applications Conference, Salt Lake City, USA, pp. 640-647, 2003.

[16] Mohammad, D.S.A., Agelis, V.G., Ra, M.V.C., "Hybrid Genetic Algorithm Approx. for Selective Harmonic Control", Energy. Convers. Manage. , Vol. 49, no. 2, pp. 131-142, 2009.

[17] Eltantawy, A. B., El-Saadany, E. F. and Salama, M. M. A., "Multilevel inverter interface of distributed generation sources for medium voltage distribution networks", in 24th Canadian Conference on Electrical and Computer Engineering(CCECE), Niagara Falls, Canada, pp.223-228, 2011.

[18] Shanono, I.H., Multi-level Converter The Future of Renewable Energy, Lambert Academic Publishing, pp. 22-44, 2012.

[19] Shehu, G.S., Kunya, A.B., Shanono, I.H. and Yalcinoz, T., "A Review of Multilevel Inverter Topology and Control Techniques", Journal of Automation and Control Engineering, Vol. 4, No. 3, pp. 233-241, 2016.

[20] Prabaharan, N., Palanisamy, K., "A comprehensive review on reduced switch multilevel inverter topologies modulation techniques and applications", Renewable and Sustainable Energy Reviews, vol. 76, pp. 1248, 2017.

[21] Awais, M., Ilyas, H., Younus, H. B., Raza, M. A., and Abbas, T., "Optimal switching angles for minimization of total harmonic distortion in single phase cascaded multilevel inverters", in 2016 19th International Multi-Topic Conference (INMIC), Islamabad, Pakistan, pp. 1-6, 2016. 